\title{
Incisivo central superior com desvio do eixo de erupção e dilacerado: recuperação ortodôntica-cirúrgica
}

\author{
Edela Puricelli* \\ Luciane Q. Closs** \\ Telmo B. Berthold***
}

\begin{abstract}
RESUMO
A intrusão de um dente decíduo numa faixa etária precose, pode causar sérios danos ao seu sucessor permanente. Um caso clínico é relatado no qual, devido a este tipo de traumatismo na dentadura decídua, houve desvio do eixo de erupçáo, com a conseqüente dilaceraçăo do dente permanente. Num acompanhamento de dois (2) anos é descrito o tratamento ortodôntico-cirúrgico, em cuja técnica é aplicada a laçada dupla.
\end{abstract}

\section{SUMMARY}

Intrusion in a primary teeth in early ages can cause serious injuries to the permanent successor. A clinical case is related in which, due to this kind of traumatism in the deciduous denture, a deviation of the eruption axis had occurred. In the period of two (2) years, is described the surgical-orthodontic treatment, in which is applied the double knoose technique.

\section{INTRODUÇÃO}

Em um estudo feito por Andreasen, Sundstrom e Rava (1), foi relatado que $40 \%$ dos jovens examinados apresentavam alteraçōes na forma e/ou estrutura de seus dentes permanentes, as quais poderiam ser decorrentes de traumatismo na dentadura decídua. A dilaceraçăo radicular estava presente em $3 \%$ dos casos.

Quando houver a intrusão traumática de um dente anterior decíduo por volta de um (1) a quatro (4) anos, poderăo ocorrer danos ao permanente devido a íntima relação do ápice destes dentes com seus sucessores permanentes em desenvolvimento. Conforme o estágio de formação do dente permanente $\theta$ a intensidade do trauma, poderăo ocorrer desde pequenas hipoplasias na coroa dentária até, nas intrusōes mais severas, grandes deslocamentos da coroa do dente permanente. Este deslocamento poderá provocar uma dilaceração radicular, pois a raiz continua sua formaçăo no mesmo sentido anterior ao trauma, o que acarretará numa angulação entre a coroa e a raiz.

Incisivos centrais superiores retidos devido a desvios do eixo de erupçăo e dilaceração, são normalmente encaminhados à exodontia. $(3,4,5,6)$.

Contudo, se um diagnóstico precoce for feito, uma tentativa ortodóntica-cirúrgica de reposiçảo do dente em sua posiçaão normal, poderá ser feita com sucesso. A aplicação de dois (2) aportes metálicos,

vai permitir a tração ortodôntica nas direçōes necessárias: esta técnica cirúrgica proporciona a erupçăo do dente, favorecendo a rizogênese com direçāo normal, sem exposiçāo do ápice radicular, minimizando o ângulo corono-radicular (10).

\section{CASO CLÍNICO}

O paciente S.F.J. com sete (7) anos de idade, apresentava $\circ$ dente $21 \mathrm{em}$ posição por seis (6) meses, enquanto o seu

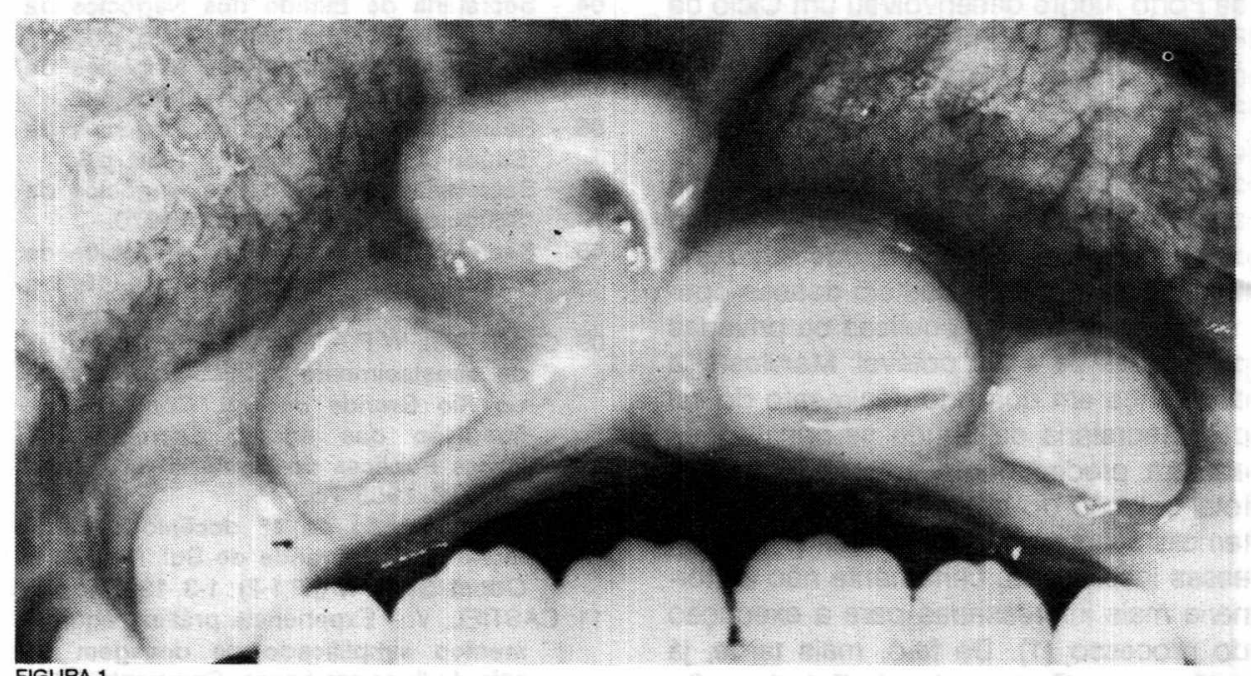

FIGURA 1

homólogo nāo demonstrava sinais de erupçāo. Na história clínica foi relatado um traumatismo dentário no $51 \mathrm{com}$ a conseqüente intrusão por volta de três (3) anos de idade. Houve rompimento do fei- xe vásculo nervoso do dente, o que levou à necrose pulpar do mesmo. Foi feito tratamento endodôntico com pasta reabsorvivel e o dente se manteve por mais dois (2) anos.

No exame clínico (Figs. 1 e 2) e radiográfico (Panorâmica, Telerradiografia e Periapical - Figs. 3,4 e 13). Se constatou a retençăo do $11 \mathrm{com}$ desvio do eixo de erupção e dilaceração, estando a coroa dentária com o bordo incisal posicionado
* Profa. Doutora Adjunta no Dep. de Ortopedia e Cirurgia da FO/UFRGS

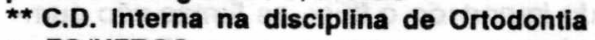
na FO/UFRGS

*** Prof. de Ortodontia na FO/UfRGS e PUC/RS

\begin{tabular}{|l|l|l|l|l|l|l|}
\hline R. Fac. Odontol. & Porto Alegre & V.32 & N. 2 & p.22-25 & NOVEMBRO & 1991 \\
\hline
\end{tabular}


para vestibular (na altura do terço apical das raízes do 12 e 21). 0 dente nảo apresentava rizogênese completa, correspondendo ao estágio 8 de Nolla (8). 0 paciente ainda apresentava mordida aberta devido à interposiçăo lingual.

\section{TRATAMENTO}

Mesmo não se tendo um prognóstico favorável do caso, achamos que a tentativa seria válida.

Primeiramente foi colocado um apareIho removível com duas molas para recuperar e, posteriormente, manter o espaço para o correto posicionamento do 11. Ainda foi adicionado uma grade, para corrigir a mordida aberta, evitando a interposiçāo lingual.

Sob efeito da analgesia local, foi realizada a exposiçăo cirúrgica do dente, desde o colo até o bordo incisal. Foram aplicados 2 (dois) apêndices metálicos laço cirúrgico - para o tracionamento.

Uma laçada contorna firmemente o colo dentário, permitindo nesse caso, a tração vertical $\theta$ palato-vestibular do processo radicular. A outra laçada fixada com resina composta na face vestibular da coroa, vai permitir rotaçāo do dente no sentido vestíbulo-palatino além de potencializar a traçāo vertical.

O retalho muco-gengival é recolocado em posiçăo, recobrindo perfeitamente o dente. As extremidades distais dos laços cirúrgicos ficam expostas na cavidade bucal numa situaçāo paralelo-vertical. Os chicotes metálicos sāo dobrados, criando-se uma situação de alça para a aplicação dupla de forças. Estas deverão atuar isoladas ou simultaneamente durante o período de traçăo ortodóndica. Neste caso o tratamento foi feito com o uso alternado das forças.

Devido a dificuldade de colocaçăo dos elásticos no aparelho removível, e o paciente apresentar mordida aberta, optouse pelo tracionamento com ancoragem simultânea nos dentes ântero-inferiores. Foram colocados "brackets" nos dentes $32,31,41,42$ e confeccionado um segmento de arco com ganchos.

Após três meses, com a diminuiçāo da mordida aberta, retirou-se a grade da placa.

Após cinco meses de uso de elásticos ancorados no segmento inferior para o tracionamento do 11 , foi suspenso o apoio de traçāo no arco inferior, evitando assim a extrusăo excessiva destes dentes.

Nova placa com ganchos soldados no Hawley foi confeccionada (Figs. 5 e 6). Após cinco meses de uso contínuo de elásticos presos ao Hawley, constatou-se uma real movimentação do dente no sen-
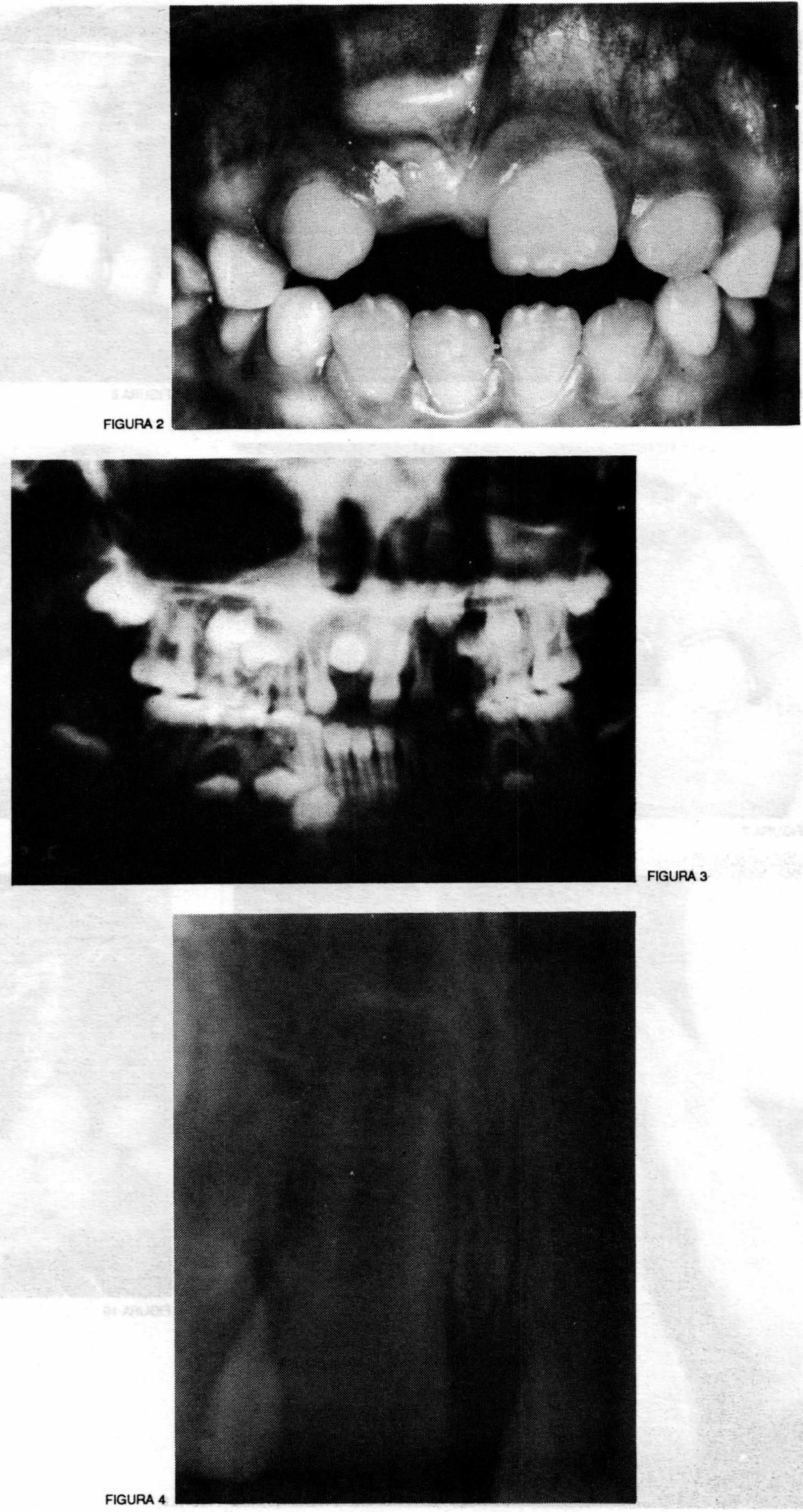


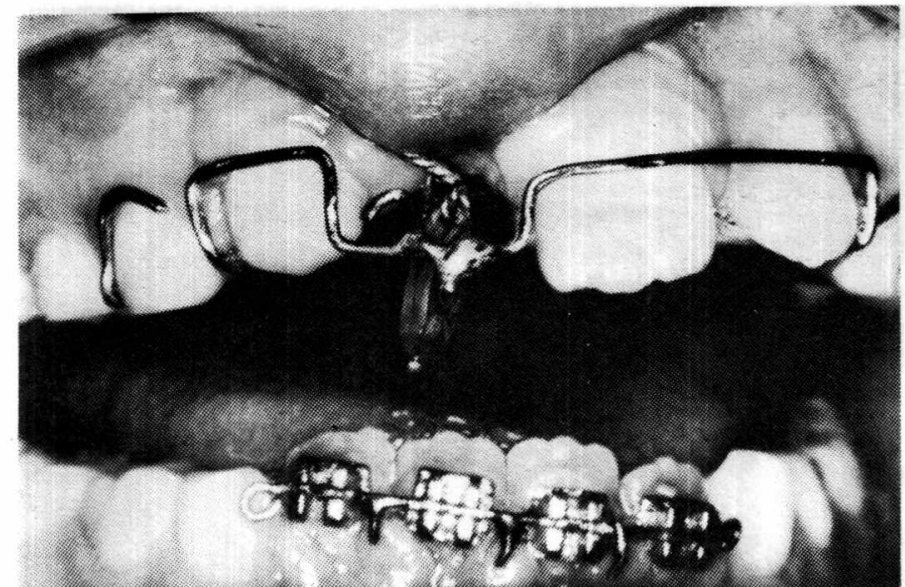

FIGURA 5
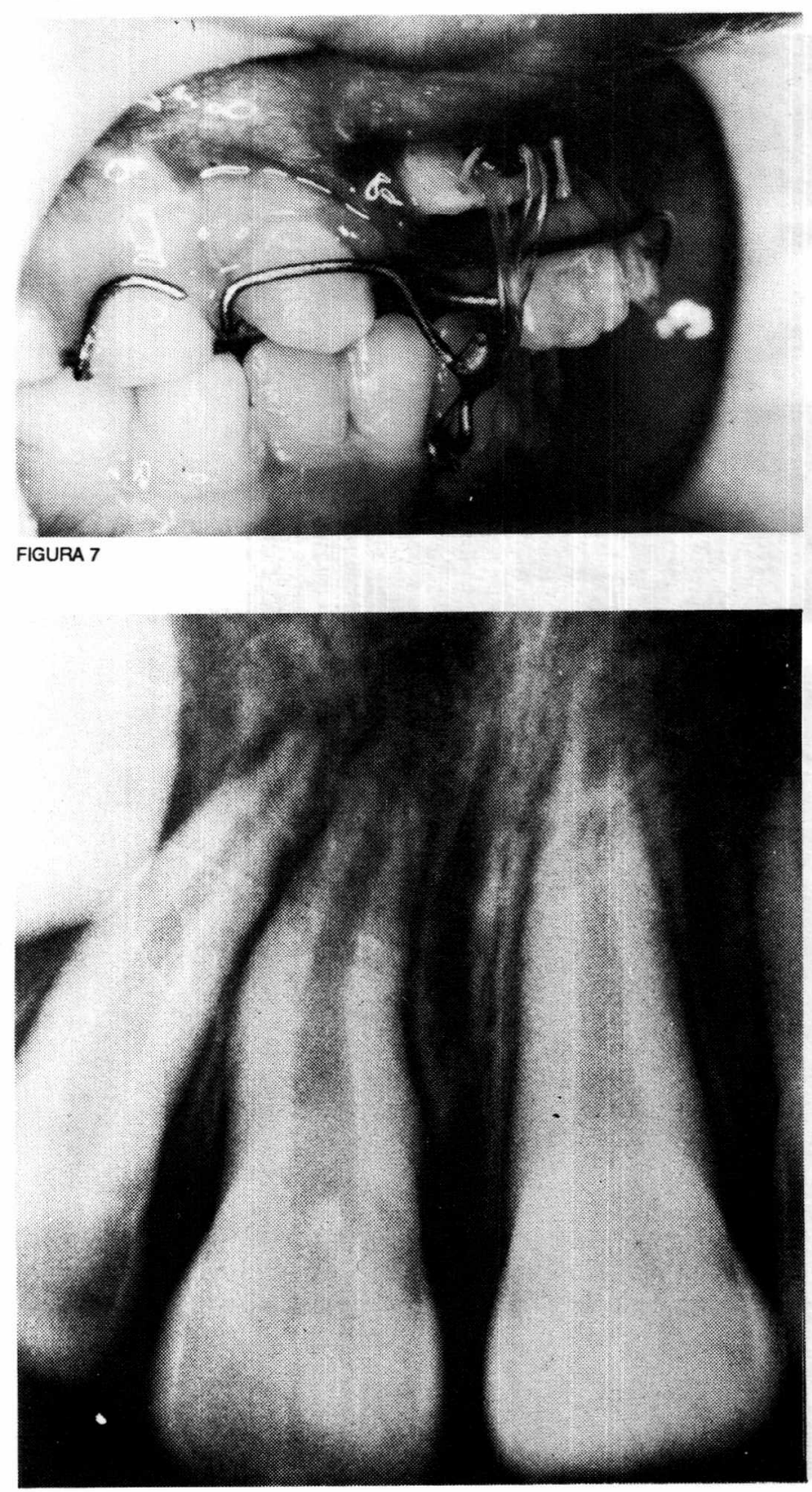

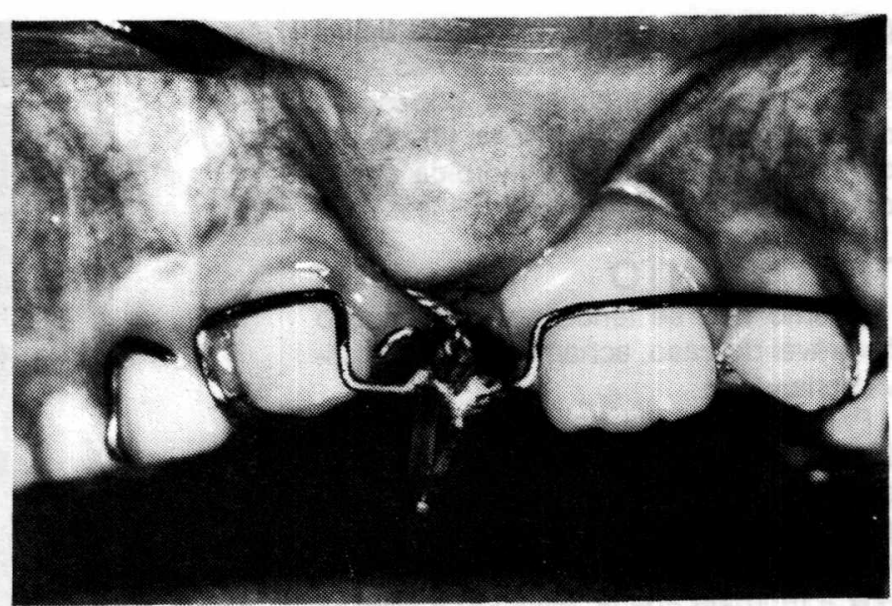

FIGURA 6

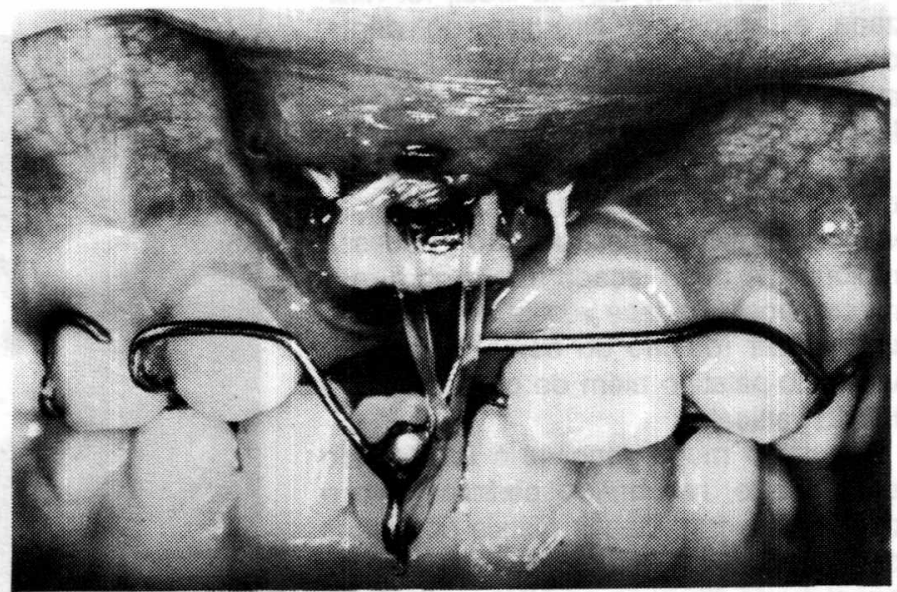

FIGURA 8

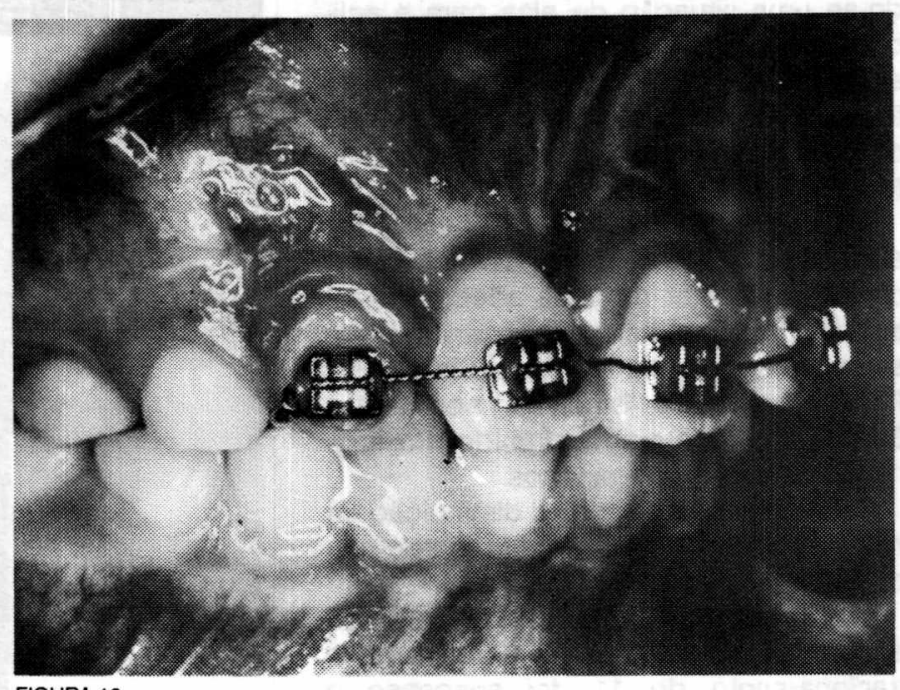

FIGURA 10 
tido oclusal, sem no entanto romper a mucosa.

Onze meses após o início da traçāo ortodóntica, os fios metálicos que compunham a laçada dupla foram removidos. Nesse mesmo tempo fez-se a exposiçāo parcial da coroa dentária com remoçāo da fibrose gengival sobre-estendida na área do bordo incisal.

Para se continuar o tracionamento, foi colado um gancho na face vestibular do dente para o uso de elásticos. (Figs. 7 e 8)
Após a completa verticalizaçāo do dente e controle radiográfico, foram colados "brackets" na regiāo ântero-superior, para um melhor alinhamento dentário e fechamento dos diastemas. (Figs. 9, 10, $11 \mathrm{e}$ 12).

Como contençāo, utilizou-se uma placa com arco vestibular de Hawley.

\section{CONCLUSÃO}

$\mathrm{Na}$ maioria dos casos relatados, principalmente na literatura odontopediátrica, um dente nas condiçōes do apresentado neste caso, teria um prognóstico sombrio e provavelmnte indicado para exodontia.

Destaca-se aqui, mais uma vez, o valor de um diagnóstico em idades precoces que, associado ao tratamento orto-cirúrgico, recupera dentes de fundamental importância estética e funcional.

Através deste tratamento, pretendemos devolver ao pequeno paciente as condiçōes naturais para um desenvolvimento dentário normal, sem a presença de próteses numa idade tāo precoce.

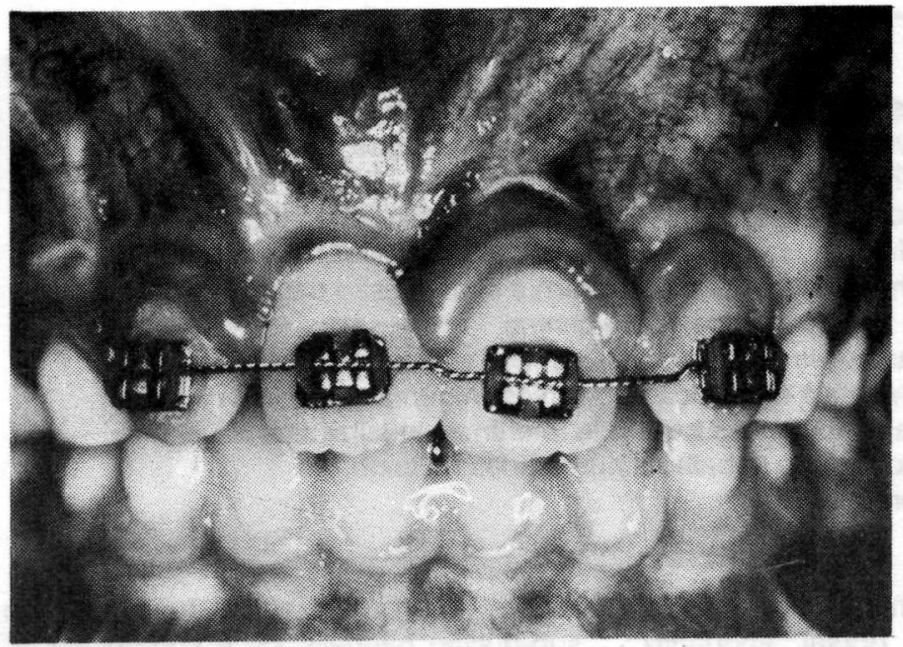

FIGURA 11

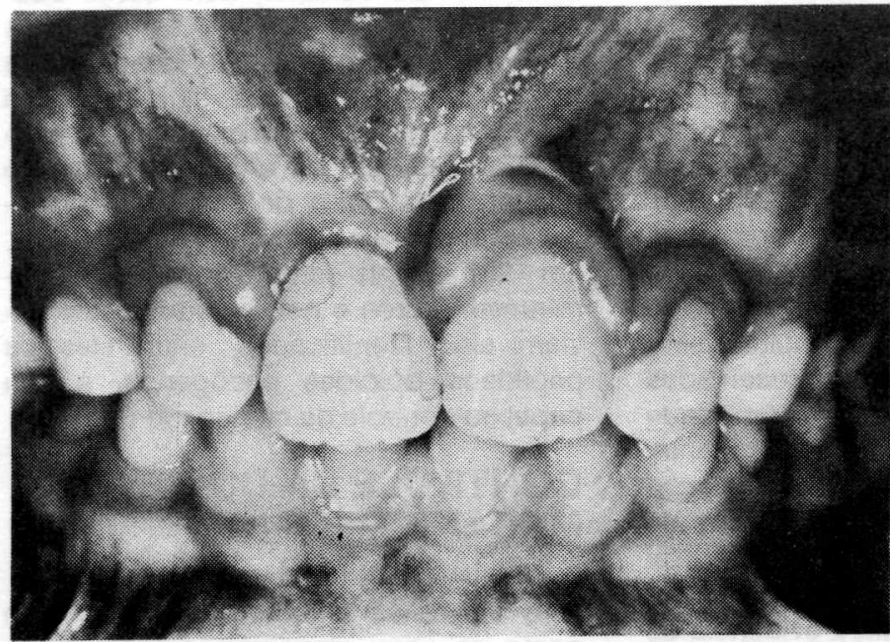

FIGURA 12

\section{REFERÊNCIAS BIBLIOGRÁFICAS}

01. ANDREASEN, J.O., SUNSTROM, R.J. - The effect of traumatic injuries to primary teeth on their permanent successors. Scand. J. Dent. Res. 1971. 79:219-283.

02. BOBRAK, et all. - Orthodontic management of traumatically intruded incisor - a case report. J. Indiana Dent. Assoc. 1984. May. 56(5):181-5.

03. BECKER, A.; STERN, N.; ZELCER, Z. - Utilization of a dilacerated incisor tooth as its own space maintainer. Journal of Dentistry. 1976. 4(6):263-264.

04. CRABB, J.J.; EDMONSON, H.D. - Dilaceration of both upper central incisor teeth: a case report. Journal of Dentistry. 1975. 3(5) :223-224 .

05. EDLER, R. - Dilaceration of upper central and lateral incisors: a case report. $\mathrm{Br}$. Dent. J. 135, 331-332.

06. LOWE, P.L. - Dilaceration caused by direct penetrating injury. Br. Dent. J. 1985. 159:373-374.

07. MC DONALD, AVERY D. - Odontopediatria.

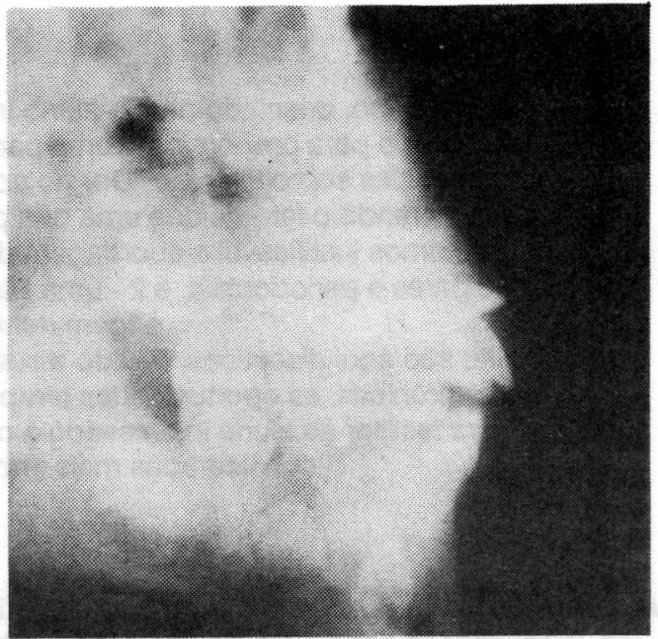

FIGURA 13

\begin{tabular}{|l|l|l|l|l|l|l|}
\hline R. Fac. Odontol. & Porto Alegre & V. 32 & N. 2 & p.22-25 & NOVEMBRO & 1991 \\
\hline
\end{tabular}

